\title{
Tuning the morphological appearance of iron(III) fumarate: impact on material characteristics and biocompatibility
}

\author{
Patrick Hirschle, ${ }^{1}$ Christian Hirschle, ${ }^{2}$ Konstantin Böll, ${ }^{3}$ Markus Döblinger, ${ }^{1}$ Miriam Höhn, ${ }^{4}$ Joshua M. \\ Tuffnell, ${ }^{5,6}$ Christopher W. Ashling, ${ }^{5}$ David A. Keen, ${ }^{6}$ Thomas D. Bennett, ${ }^{5}$ Joachim O. Rädler, ${ }^{7}$ Ernst \\ Wagner, ${ }^{4}$ Michael Peller, ${ }^{3}$ Ulrich Lächelt, ${ }^{4}$ Stefan Wuttke ${ }^{1,8,9, *}$ \\ ${ }^{1}$ Department of Chemistry and Center for NanoScience (CeNS), LMU Munich, Butenandtstraße 1181377 Munich, Germany \\ ${ }^{2}$ Ruhr-Universität Bochum, Institut für Geologie, Mineralogie und Geophysik, Universitätsstraße 150, 44801 Bochum, \\ Germany \\ ${ }^{3}$ Department of Radiology, University Hospital, LMU Munich, 81377 Munich, Germany \\ ${ }^{4}$ Department of Pharmacy and Center for NanoScience (CeNS), LMU Munich, Butenandtstraße 5-13 81377 Munich, Ger- \\ many \\ ${ }^{5}$ Department of Materials Science and Metallurgy, University of Cambridge, 27 Charles Babbage Road, Cambridge CB3 \\ OFS, United Kingdom \\ ${ }^{6}$ ISIS Facility, Rutherford Appleton Laboratory Harwell Campus, Didcot, Oxon, OX11 0QX, UK \\ ${ }^{7}$ Faculty of Physics, Soft Condensed Matter, Ludwig-Maximilians-University, Munich, Germany \\ ${ }^{8}$ School of Chemistry, College of Science, University of Lincoln, Brayford Way, Brayford Pool, Lincoln LN6 7TS, United \\ Kingdom \\ ${ }^{9}$ BCMaterials, Basque Center for Materials, UPV/EHU Science Park, 48940 Leioa, Spain
}

Iron(III) fumarate materials are well suited for biomedical applications as they feature biocompatible building blocks, porosity, chemical functionalizability, and magnetic resonance imaging (MRI) activity. The synthesis of these materials however is difficult to control and it has been challenging to produce monodisperse particle sizes and morphologies that are required in medical use. Here, we report the optimization of iron(III) fumarate nano and microparticles synthesis by surfactant-free methods, including room temperature, solvothermal, microwave, and microfluidic conditions. Four variants of iron(III) fumarate with distinct morphologies were isolated and are characterized in detail. Structural characterization shows that all iron(III) fumarate variants exhibit the metal-organic framework (MOF) structure of MIL-88A. Nanoparticles with a diameter of $50 \mathrm{~nm}$ were produced, which contain crystalline areas not exceeding $5 \mathrm{~nm}$. Solvent-dependent swelling of the crystalline particles was monitored using in-situ X-ray diffraction. Cytotoxicity experiments showed that all iron(III) fumarate variants feature adequate bio-tolerability and no distinct interference with cellular metabolism at low concentrations. Magnetic resonance relaxivity studies using clinical MRI equipment, on the other hand, proved that the MRI contrast characteristics depend on particle size and morphology. All in all, this study demonstrates the possibility of tuning the morphological appearance of iron(III) fumarate particles and illustrates the importance of optimizing synthesis conditions for the development of new biomedical materials.

\section{Introduction}

There is a sustained demand for new colloidal nano and microparticles in biomedical applications such as drug delivery, imaging, cell labeling and cancer therapy. ${ }^{1-10}$ In the last two decades many new material classes have been developed that can be used in these applications, but these advances have also identified new problems which have to be tackled. ${ }^{11-13}$ One such problem is the feasibility of synthesis; biomedical applications desire particles that are simple to synthesize, ideally under aqueous conditions. Products should be of high purity, and monodisperse in size and shape to ensure in vitro and in vivo reproducibility. ${ }^{9}$ In general, particles destined for drug delivery should be highly porous and have functionalizable inner and outer surfaces to control the loading and release of drugs, to equip them with imaging capabilities, to improve their colloidal stability, and to control their interaction at the nano-biointerface. Of course, biomedical applications require intense study and control over the potential toxicity of the compounds - a problem that can be addressed by creating materials from biocompatible building blocks and ensuring biodegradability. ${ }^{8,9}$

Iron(III) fumarate excels in all of these categories and is therefore a promising candidate for biomedical use. This material has been used to produce crystalline solids of various particle sizes for various applications (Table 1). In its crystalline form, iron(III) fumarate exhibits the metal-organic framework (MOF) structure of MIL-88A. ${ }^{14}$ The hexagonal crystal structure of this coordination framework consists of $\mathrm{Fe}^{3+}$ ions arranged into $\mathrm{Fe}_{3} \mathrm{O}_{16}$ iron-oxo trimers that are in turn connected by the bridging ligand fumaric acid (Figure $\mathrm{S} 1$ ). The resulting material is a microporous, flexible hybrid structure. Solvent and other guest molecules can penetrate into the pores and shift the lattice parameters such that its pore volume increases in a process called lattice "breathing". ${ }^{15-18}$ Iron(III) fumarate is considered well tolerated since its components are ubiquitous in the human body; fumaric acid is a metabolite of the citric acid cycle, and 


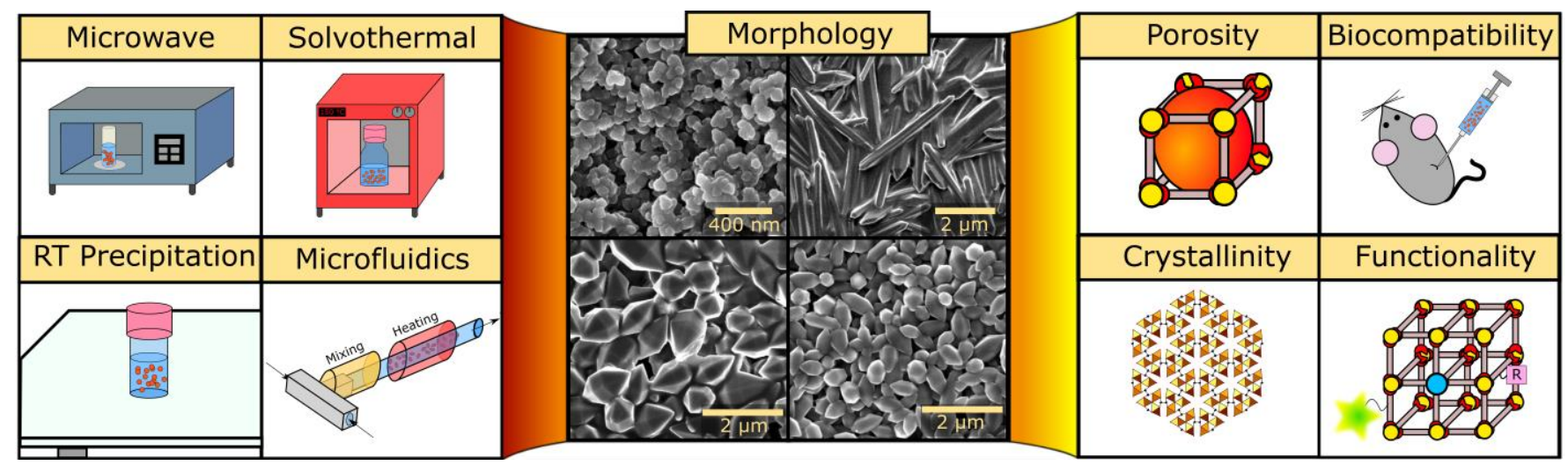

Figure 1. Schematic illustration of this work from left to right: The synthesis of iron(III) fumarate particles was optimized using four different synthesis approaches. By controlling reaction parameters four different iron(III) fumarate variants depicted here in scanning electron micrographs have been isolated. These particles were then further characterized by biological and physicochemical techniques to understand the connection between morphology, size, porosity, functionality and biocompatibility.

iron is a trace element in our body and essential co-factor of many enzymes and proteins. Iron(III) fumarate particles offer remarkable functionality. Iron(III) fumarate nanoparticles have shown great compatibility with biological coatings such as exosomes $^{19,20}$ and liposomes ${ }^{20}$. Coordinatively unsaturated metal-centers on the particles' surface can bind Lewis bases, enabling post-synthetic modification. ${ }^{21}$ Therefore the synthetic material can be post-modified to feature hydrophilic surproperties ${ }^{22}$ or fluorescent centers ${ }^{23}$. Other functionalization approaches can be conducted during particle synthesis and introduce monovalent capping agents at the particle surface that carry functional groups. ${ }^{24}$

In addition to this functionalizability, iron(III) fumarate offers important intrinsic functionality that makes it well suited for clinical imaging: crystalline iron(III) fumarate hosts a significant proportion of paramagnetic $\mathrm{Fe}^{3+}$ ions, which qualifies the framework as a potential contrast agent in magnetic resonance imaging (MRI). ${ }^{25,} 26$ Furthermore, gold functionalized iron(III) fumarate particles have performed well as contrast agents in other clinical imaging methods such as computer tomography and photoacoustic imaging. ${ }^{26}$ As both a biocompatible and functionalizable material, it is no surprise that there are numerous reports of iron(III) fumarate nano and microparticles being used as potential drug carriers. ${ }^{19-21,23,25,27,28}$ A summary of the most important biomedical and non-biomedical applications of the material are shown in Table 1. All of these applications are based on iron(III) fumarate, however their material properties such as particle size and shape do not appear standardized.

Table 1. Applications of iron(III) fumarate in the literature.

\begin{tabular}{|c|c|c|}
\hline Iron(III) fumarate type & Application & Pub. \\
\hline \hline \multirow{4}{*}{ Nanoparticles } & Drug delivery & $\begin{array}{c}19,20, \\
23,25,27,28\end{array}$ \\
\cline { 2 - 3 } & Imaging & 25,26 \\
\cline { 2 - 3 } & Sensing & $24,29,30$ \\
\cline { 2 - 3 } & Catalysis & 31,32 \\
\hline \multirow{4}{*}{ Microparticles } & Water purification & 33 \\
\cline { 2 - 3 } & Catalysis & $34-40$ \\
\cline { 2 - 3 } & Electrochemistry & $38,41,43$ \\
\cline { 2 - 3 } & Gas storage & 42 \\
\hline \multirow{4}{*}{ Not specified } & Gas storage & 43,44 \\
\cline { 2 - 3 } & Catalysis & 21 \\
\cline { 2 - 3 } & Drug Delivery & 21 \\
\cline { 2 - 3 } & &
\end{tabular}

To date, synthesis protocols of monodisperse iron(III) fumarate particles are not well established. ${ }^{46}$ Advances that were made to characterize the crystallization of this structure either rely on the usage of modulating additives or fail to characterize the particles' functionality and biocompatibility. ${ }^{27,30,47-}$ ${ }^{49}$ Mastering the synthesis of iron(III) fumarate particles and understanding the relationship between their morphology, structure and their material and biological properties are imperative to unlock their potential for biomedical purposes. The study presented here therefore serves multiple purposes: (i) to systematically study the relationship between synthesis conditions (e.g. heat source, reaction parameters, solvent, reactant concentration) and the morphology and crystallinity of iron(III) fumarate particles produced; (ii) to investigate the impact of morphology on the particles' intrinsic material properties (e.g. MRT activity and porosity); and (iii) to explore their biocompatibility and connect those data with the physicochemical parameters (e.g. morphology and size).

With these goals in mind, we investigated the influence of different synthesis approaches (solvothermal, microwave assisted, microfluidic heating, and simple room temperature precipitation) on the iron(III) fumarate system. By optimizing the reaction conditions such as reaction time, temperature, reactant concentration, and solvent, we were able to control the morphology of the emerging particles, which allowed us to produce four isolated distinct iron(III) fumarate variants. These particles were then further characterized to address the three aforementioned targets: First, the iron(III) fumarate variants generated under different synthesis conditions were characterized by electron microscopy, electron diffraction and X-ray diffraction. Next, nitrogen sorption, in-situ X-ray diffraction and magnetic resonance data were gathered for the particles. Finally, we tested the particles for cytotoxicity and cell association.

\section{Morphological Control of Iron(III) Fumarate}

Biomedical applications require high-quality nano and microparticles generated with reproducible synthesis protocols that can be scaled-up and yield a product with monodisperse morphology and size. The growth of nanocrystalline MOFs is typically controlled by using modulating capping agents such as surfactants and short monocarboxylic acids. ${ }^{50}$ In our study we avoid this chemical approach as it comes with adverse side effects; modulating agents are often toxic, and they tend to accumulate on the outer surface of particles. ${ }^{51}$ Therefore, in this 
section we study the formation of iron(III) fumarate particles using common heating methods like conventional and microwave ovens in addition to microfluidic reactors, a synthesis technique that has only recently captured the attention of the MOF community. ${ }^{28,52-55} \mathrm{We}$ compare particle formation in the most ubiquitous iron(III) fumarate synthesis solvent $N, N$-Dimethylformamide (DMF), and water which is the solvent of choice for any material with intended use in biomedical applications.

Synthesis in DMF Iron(III) fumarate synthesis in DMF was performed by first dissolving iron(III) chloride hexahydrate in DMF under sonication and subsequently adding a corresponding amount of fumaric acid. The resulting solution $(0.2 \mathrm{M}$ iron(III) chloride hexahydrate, $0.2 \mathrm{M}$ fumaric acid) was used as the starting solution in all of the different synthesis approaches. This reaction solution was incubated for several weeks at room temperature (RT), but no particle formation occurred, suggesting that the synthesis of iron(III) fumarate at these concentrations requires heating.

For solvothermal experiments, this stock solution was used in its concentrated $(0.2 \mathrm{M})$ form and in a tenfold diluted concentration $(0.02 \mathrm{M})$. The morphology and homogeneity of the iron(III) fumarate particles resulting from this method depend primarily on heating time. In order to provide the steep heating ramps and fast heat transfer necessary to produce well-defined nucleation and growth periods, solvothermal experiments with reaction times of less than $2 \mathrm{~h}$ were performed in reaction volumes of $1 \mathrm{~mL}$ (for more reaction details see Supporting Information). At high reactant concentrations iron(III) fumarate was produced after heating for $6 \mathrm{~h}$ at $60^{\circ} \mathrm{C}$. Increasing the temperature to $120{ }^{\circ} \mathrm{C}$ shortened the reaction time to $30 \mathrm{~min}$. These particles were micrometer-sized and exhibited homogeneous bipyramidal shape when first formed, however this homogeneity is lost upon further heating (Figure S2), which we attribute to the formation of new nucleation centers during the longer heating period. To study the influence of reactant concentration on iron(III) fumarate particle formation, the reactant concentration was lowered by a factor of 10 . This change produced highly homogeneous elongated particles (Figure S3). A tenfold reduction of the reaction time improved particle homogeneity at these low concentration conditions even further (Figure S4). Temperature decreases did not influence the resulting particle morphology but slowed down the time for particle formation (Figure S4).

Microfluidic particle growth in DMF was conducted using a single syringe setup that was fed with a premixed, high concentration solution of all precursors into PTFE tubing. The reaction mixture was pumped through a heating zone of defined length, which allowed us to manipulate the reaction time by altering the rate of the reactant flow. (Figure S5). Due to the improved heat transfer afforded by this microfluidic setup the particles crystallization time was shortened by a factor of two, to just $15 \mathrm{~min}$, and the particle size was decreased to below $1 \mu \mathrm{m}$. Lower flow rates (and therefore longer reaction times) produced larger particles (Figure S6). Prolonged use ( $2 \mathrm{~h}$ ) of this setup lead to clogging in the delicate microfluidic tubing due to particle growth on the tubing walls.

The challenge of creating steep heating and cooling ramps in DMF could be overcome by microwave heating. In these experiments reaction temperatures were adjusted in less than a minute while providing 20 times the reaction volume of the solvothermal approaches and were stopped by fast quenching in cold DMF. Compared to microfluidic synthesis microwave heating at $120{ }^{\circ} \mathrm{C}$ in a 5 minute synthesis protocol has decreased particle size by $50 \%$ (Figure S7 and Figure S8). Further decreases in reaction time yielded polydisperse particles at very low yields.

Synthesis in Water Iron(III) fumarate synthesis in water was conducted by preparing an aqueous solution of iron(III) chloride hexahydrate and adding a stoichiometric amount of fumaric acid ( $0.2 \mathrm{M}$ iron(III) chloride hexahydrate, $0.2 \mathrm{M}$ fumaric acid). The resulting suspension was used as a stock solution for further experiments. Within two minutes of preparing this reaction mixture, precipitation of spherical iron(III) fumarate nanoparticles can be observed (Figure S9). Over time, iron(III) fumarate needles embedded within a matrix of interconnected spherical nanoparticles emerged, and the micrometer-long needles completely exceeded the spherical particles after 4 days. (Figure S10). During this time, the crystallinity of the overall sample increased drastically (Figure S11). Elevated temperatures such as in solvothermal and microwave assisted growth (Figure S12 and Figure S13) enhanced the speed at which this crystallization transformation was completed. Further reaction time did not change the resulting crystal product noticeably (Figure S13). Similar to the solvothermal growth experiments in $\mathrm{DMF}$, these experiments were limited to reaction volumes of $1 \mathrm{~mL}$ for reaction times under $1 \mathrm{~h}$ to ensure a sufficiently fast heating rate.

For faster heat transfer and better control over reaction time the microfluidic setup shown schematically in Figure S5 was used. Syringe pumps that fed both aqueous iron(III) chloride and fumaric acid precursor solutions via a $\mathrm{T}$-junction into heated PTFE tubing in a $1: 1$ ratio. These experiments require fully soluble precursors, and thus reactant concentrations were lowered twentyfold. The onset of needle formation in this microfluidic reactor corresponded to the onset observed under solvothermal conditions despite the low reactant concentrations (Figure S14). Unfortunately, iron(III) fumarate quickly precipitated on the walls of the microfluidic tubing rendering the approach unfeasible for reaction times longer than $10 \mathrm{~min}$. Similar to the other aqueous synthesis approaches, under these conditions the growth of the needle morphology was preceded by the precipitation of spherical nanoparticles.

Further experiments compared the efficacy of these microfluidic experiments to solvothermal and room temperature synthesis. A tenfold diluted iron(III) fumarate solution was mixed with a stoichiometric amount of fumaric acid in a 1:1 ratio. These experiments also initially resulted in the precipitation of spherical nanoparticles of iron(III) fumarate that transformed over time into crystalline micro-needles (Figure S15). At room temperature, needle crystallization growth was considerably slowed while the microparticles grew in a more bulky shape (Figure S16).

\section{Material Characterization}

Through optimization of synthesis conditions as described above, we isolated 4 variants of iron(III) fumarate particles with notable homogeneity, morphology and scale-up potential. (Figure 2). The smallest of these particles (with diameters of $(49 \pm 12) \mathrm{nm})$ are referred to as "spherical nanoparticles". These were synthesized via RT precipitation from water. The iron(III) fumarate "dipyramidal nanoparticles" are $(400 \pm 95) \mathrm{nm}$ long and $(184 \pm 30) \mathrm{nm}$ wide, and were synthesized in a microwave reactor in DMF. "Dipyramidal microparticles" with a diameter of $(1.2 \pm 0.2) \mu \mathrm{m}$ were synthesized in 
DMF under solvothermal conditions. The needle-shaped microparticles $(10 \pm 2) \mu \mathrm{m}$ long and $(975 \pm 420) \mathrm{nm}$ wide were synthesized in water using the solvothermal method (Figure S17). The detailed synthesis conditions of these particles are described in the Supporting Information.

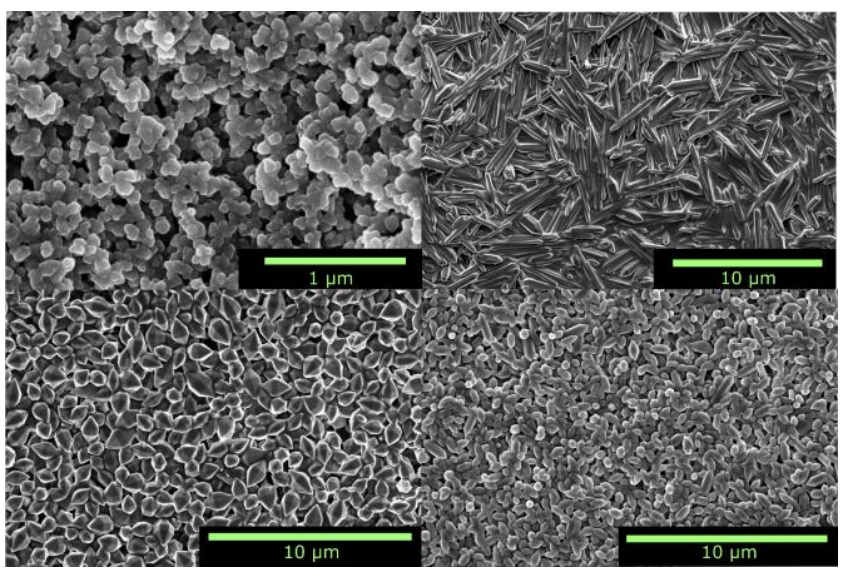

Figure 2. SEM micrographs depicting the morphology of the four variants of iron(III) fumarate that are used for further characterization. Top left: spherical nanoparticles, top right: needle-shaped microparticles, bottom left dipyramidal microparticles, bottom right: dipyramidal nanoparticles.

\section{Chemical and Colloidal stabiltiy}

In order to test the particles' behavior in solution, dynamic light scattering (DLS, see Figure S23 and Table S3) and zeta potential measurements (see Figure S24 and Table S4) were performed. These experiments show that both nanoparticle variants form colloidally stable suspensions in to water and ethanol. In HBG buffer (10 mM HEPES, $5 \%$ glucose, pH 7.4) the smaller spherical nanoparticles did exhibit slight signs of agglomeration while the dipyramidal nanoparticles were not affected. In HEPES buffer (10 mM, pH 7.4) both nanoparticle types showed signs of agglomeration. This was further confirmed in zeta-potential measurements, where the particles generally exhibited a positive zeta potential in water $(10-20 \mathrm{mV}$, $\mathrm{pH} 7.0)$ or negative zeta-potential in HBG buffer $(-10 \mathrm{mV}$ to $-20 \mathrm{mV}, \mathrm{pH} 7.4$ ) while being close to $0 \mathrm{mV}$ in HEPES buffer (pH 7.4).

Chemical stability assessments have shown that the needle microparticles and both nanoparticle morphologies retain their shape when incubated in cell medium for $24 \mathrm{~h}$ (Dulbecco's Modified Eagle's Medium, See Figure S18), while the dipyramidal microparticle morphology show beginning signs of degradation. Overall the particles feature excellent long-term storage capabilities as they can be stored in ethanol at RT for many months (Figure S19 - Figure S22).

\section{$\mathrm{X}$-Ray diffraction}

X-ray data was gathered for all 4 morphologies using powdered samples generated via RT vacuum drying of ethanolic particle dispersions (Error! Reference source not found.). Both microparticle types and the dipyramidal nanoparticles depict crystallinity with X-ray diffraction patterns corresponding to MIL-88A ${ }^{16}$ (Figure S1). Lattice parameter refinements of these 3 samples resulted in very similar values (Table 2 ). The small deviations can be attributed to the drying process of the flexible MIL-88A structure and distortion of the lattice. The spherical nanoparticles, on the other hand, appear amorphous in these X-ray diffraction experiments. However, we stress that this, as demonstrated later in this work, is only an effect of the small particle size. This highlights a key misconception in current MOF literature - i.e. confusion between nanocrystalline, and amorphous samples.

Table 2. Lattice parameters of the three crystalline iron(III) fumarate samples.

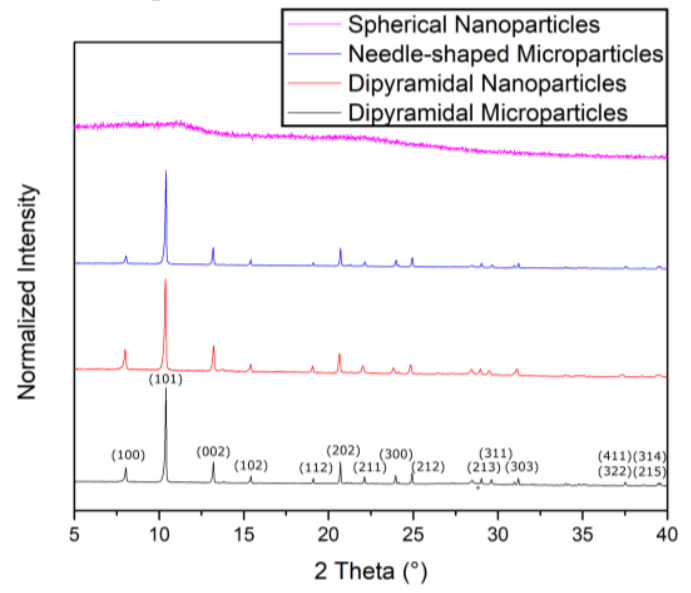

Figure 3. X-ray diffraction patterns of the morphologically distinct iron(III) fumarate samples

\begin{tabular}{|c|c|c|}
\hline Iron fumarate variant & $\mathbf{a}(\AA \mathbf{)}$ & $\mathbf{c}(\mathbf{\AA})$ \\
\hline \hline Needle-Shaped Microparticles & $12.8678(09)$ & $13.5139(14)$ \\
\hline Dipyramidal Nanoparticles & $12.9307(15)$ & $13.4325(27)$ \\
\hline Dipyramidal Microparticles & $12.8701(12)$ & $13.4870(17)$ \\
\hline
\end{tabular}

\section{Thermogravimetric analysis}

To more carefully identify the chemical relationship between the crystalline and the spherical iron(III) fumarate nanoparticle samples, we performed thermogravimetric measurements. The thermogravimetric data for all four samples are shown in Figure S25 and Table S5. The degradation behavior of the samples matches literature data for the MOF MIL-88A. ${ }^{56}$ All four samples undergo a two-step degradation process which indicates a similar chemical composition. After initial drying of the samples only a low amount (around 5-8 wt\%) of residual solvent is physisorbed to the surface. The onset of the degradation at $259{ }^{\circ} \mathrm{C}-285{ }^{\circ} \mathrm{C}$ caused by the degradation of fumaric acid. ${ }^{30} \mathrm{Af}-$ ter decomposition of the organic component (52-57\% of the total sample mass), XRD indicates that the residual mass of the samples (the remaining 37-41\%) corresponds to a final composition of an iron(III) oxide than can be identified as hematite (Figure S25).

\section{Electron diffraction}

For further structural and morphological characterization of the less crystalline spherical nanoparticles, transmission electron microscopy (TEM) was performed. TEM images showed particles of uniform size between 20-30 nm (Figure 4). Several particles exhibited lattice fringes that quickly vanish during illumination. More gentle electron diffraction (ED) of larger areas resulted in broadened Bragg-rings confirming that a substantial percentage of the particles exhibit crystalline domains (Figure 4). ED patterns match the lattice distances as well as the expected intensity distribution for MIL-88A. ${ }^{16}$ Figure 4 shows a comparison of an experimental ED pattern after azimuthal integration and background subtraction and an ED simulation of 
iron(III) fumarate with MIL-88A structure. The best fit with respect to reflection broadening was obtained by the Scherrer equation: $3.5 \mathrm{~nm}$ along the $a$ - and $b$-axes and approximately 1
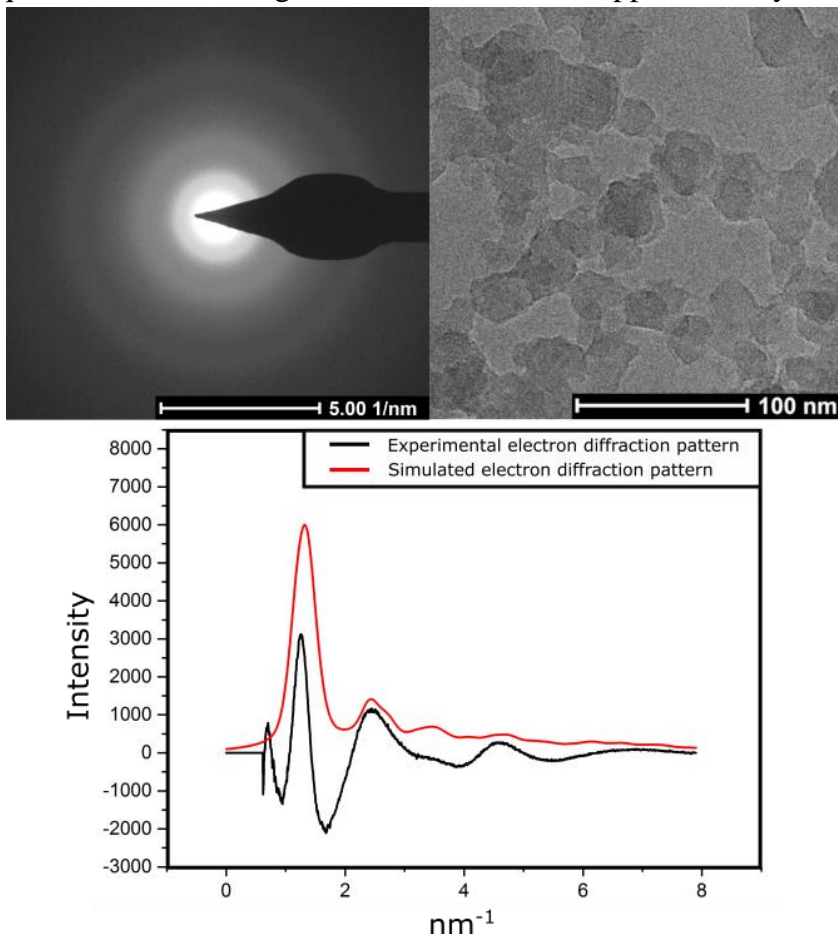

Figure 5. a) Electron diffraction pattern and b) TEM micrograph of spherical iron(III) fumarate nanoparticles. c) Azimuthally integrated electron diffraction pattern after subtraction of the mean scattering intensity (black) compared to the theoretical diffraction pattern of MIL-88A nanoparticles (red).

$\mathrm{nm}$ along the $c$-axis of the hexagonal unit cell.

\section{Pair distribution function analysis}

To complement the data acquired from electron diffraction, $\mathrm{X}$-ray total scattering experiments were performed at the I15-1 beamline at the Diamond Light Source, UK $\left(\lambda=0.161669 \AA^{-1}\right)$, on all four samples. The total scattering structure factors $S(Q)$ s (Fig. S27) were extracted after appropriate data corrections. ${ }^{57}$ The sharp Bragg features visible in the $S(Q)$ for the spherical nanoparticles clearly identify the sample as crystalline, and therefore distinct from amorphous solid or metal-organic framework glasses, where only smooth features in the structure factors are observed. ${ }^{58,59}$ The pair distribution functions, $D(r)$ for all four samples were obtained upon Fourier Transform (Fig. 5). Identical atom-atom correlations are evident up to ca. $12 \AA$. PDFgui software ${ }^{60}$ was used to identify the atom-atom correlations responsible for peaks in the $0-12 \AA$ region (Fig. S28). These assignments are labelled in the PDFs (Fig. 5), and show that the correlations appear due to near identical links between $\mathrm{Fe}_{3} \mathrm{O}$ clusters. Above $12 \AA$, i.e. the medium range order, correlations within the spherical nanoparticles reduce drastically, which is broadly consistent with the electron microscopy data and the nanoparticulate nature of the sample. It is also interesting to note that the sample of dipyramidal microparticles is dis-

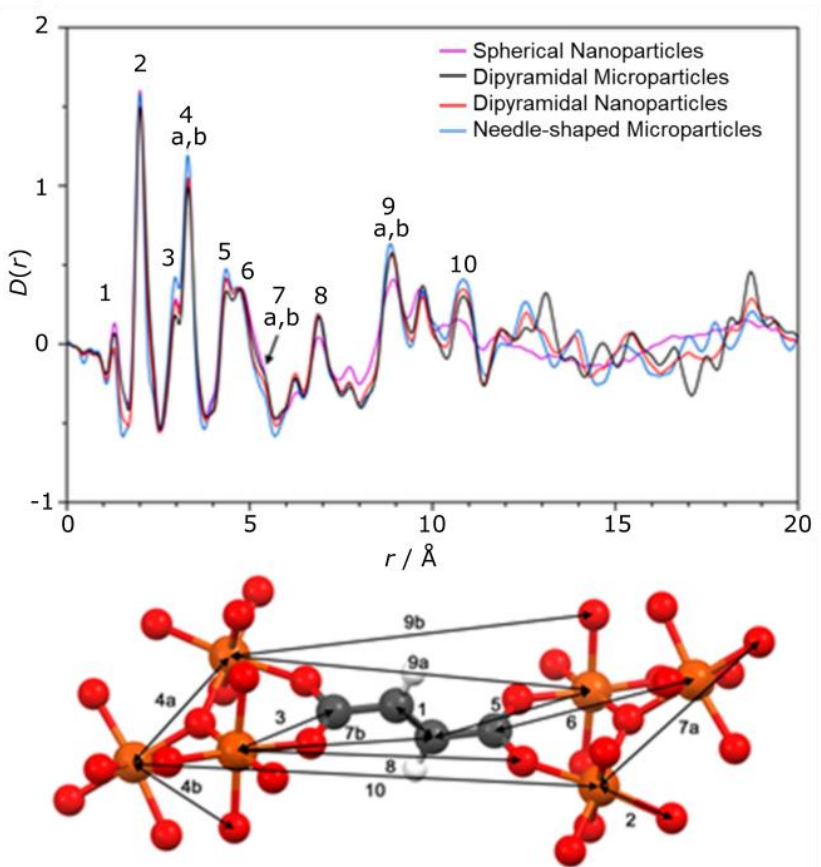

Figure 4. Pair distribution functions $D(r)$ (upper) and corresponding labelled partial structure of MIL-88A showing two iron oxide metal clusters linked by a fumarate ligand (lower) (red - oxygen, orange - iron, dark grey - carbon, white - hydrogen).

similar at this scale to both ther the needle or dipyramidal nanoparticle sample, though continues to display crystallinity to ca. $40 \AA$ (Fig. S29).

\section{Nitrogen sorption}

Porous materials are excellent candidates for drug delivery systems because their vast internal surface area is readily accessible via pores. To determine the surface area of the iron(III) fumarate samples nitrogen sorption experiments were performed and analyzed with the BET method. All samples show surface areas of 120 to $450 \mathrm{~m}^{2} / \mathrm{g}$ (Table S7) in agreement with literature values, which range from 15 to $580 \mathrm{~m}^{2} / \mathrm{g}$ depending on reaction conditions and sample preparation methods. ${ }^{23,}, 37,42$ As particle size decreases the experimentally determined BET surface areas of the particles increase. This effect can partially (30\%) be explained by the increased surface to volume ratio due to the nano dimensions of the particles (see supporting Information "Calculation of the theoretical surface depending on particle size"). Additionally we attribute the increased surface area to texturing during the drying of the particles that results in an increasing slope in the sorption isotherms for the smaller particle types after their micropores are filled (Figure S30). All iron(III) fumarate variants (Figure S31) show a similar pore size distribution (11-13 $\AA$ ). The aforementioned texturing effect can also be monitored in the pore size distributions as decreasing particle size leads to mesopores in the smaller spherical nanoparticles and dipyramidal nanoparticles.

\section{Breathing behavior}

While nitrogen sorption experiments can predict the surface area of a material, the actual loading and release of potential drugs is conducted in solvent systems. The MIL-88A structure of crystalline iron(III) fumarate is known for its flexible pores that expand upon solvent incorporation. ${ }^{16}$ The data shown in Figure S32-S34 is generated from in-situ X-ray diffraction on each of the higher crystallinity iron(III) fumarate variants using 
various solvents that would typically be encountered in biological applications. During these experiments the particles retained their crystallinity for several hours. Powder XRD patterns were used to refine the lattice parameters of the different iron(III) fumarate variants in their respective solvent combinations. As shown in Table 3, the lattice dimensions of these iron(III) fumarate variations in each of the different solvent systems was controlled with a volume change of up to $12 \%$ as solvent conditions changed, regardless of morphology.

Table 3. Lattice parameter evolution upon exposure of the higher crystalline iron(III) fumarate variants to various solvents.

\begin{tabular}{|c|c|c|c|}
\hline Solvent & a $(\AA ̊)$ & c $(\AA ̊)$ & Volume \\
\hline \multicolumn{4}{|c|}{ Needle-shaped Microparticles } \\
\hline DMSO & $14.506(21)$ & $11.828(15)$ & $2155.4(38)$ \\
\hline $\mathrm{H}_{2} \mathrm{O}$ & $13.830(8)$ & $12.702(6)$ & $2103.9(14)$ \\
\hline EtOH & $13.636(5)$ & $12.812(4)$ & 2063.2(9) \\
\hline $\mathrm{MeOH}$ & $12.863(6)$ & $13.584(6)$ & $1946.4(11)$ \\
\hline DMF & $12.92(3)$ & $13.385(19)$ & $1933.7(37)$ \\
\hline \multicolumn{4}{|c|}{ Dipyramidal Nanoparticles } \\
\hline DMSO & $14.620(4)$ & $11.722(4)$ & $2169.9(8)$ \\
\hline $\mathrm{H}_{2} \mathrm{O}$ & $13.880(21)$ & $12.711(4)$ & $2120.7(39)$ \\
\hline EtOH & $13.616(8)$ & $12.844(7)$ & $2062.1(15)$ \\
\hline $\mathrm{MeOH}$ & $12.90(6)$ & $13.60(3)$ & $1961.3(113)$ \\
\hline $\mathrm{DMF}$ & $12.820(7)$ & $13.638(12)$ & $1941.0(19)$ \\
\hline \multicolumn{4}{|c|}{ Dipyramidal Microparticles } \\
\hline DMSO & $14.647(13)$ & $11.728(9)$ & $2178.9(27)$ \\
\hline $\mathrm{H}_{2} \mathrm{O}$ & $13.873(14)$ & $12.659(10)$ & $2109.9(25)$ \\
\hline EtOH & $13.629(10)$ & $12.835(8)$ & $2064.8(17)$ \\
\hline $\mathrm{MeOH}$ & $12.86(10)$ & $13.585(11)$ & $1945.8(20)$ \\
\hline DMF & $12.829(9)$ & $13.625(8)$ & 1942.1(16) \\
\hline
\end{tabular}

\section{MRI measurements}

MIL-88A nanoparticles proved to be excellent MRI contrast agents during in vivo experiments. ${ }^{61}$ Contrast between different tissues occurs because the protons of water molecules in different tissues exhibit different longitudinal and transverse relaxation times in a magnetic field. MRI contrast agents enhance these differences further by decreasing the longitudinal $\left(T_{1}\right)$ or transverse $\left(\mathrm{T}_{2}\right)$ relaxation times of the tissues that house them. The MOF MIL-88A is believed to influence this behavior because its paramagnetic iron(III) centers are imbedded in a porous framework and are therefore easily accessed by water. ${ }^{61,62}$ The inverse of these relaxation times, i.e. $R_{i}=1 / T_{i}(i=1,2)$, are determined to measure the strength of a potential contrast agent at particular concentrations. Typically, the $R_{i}$ values display a linear dependency on the concentration of the contrast agent; in such cases, the slope is called the relaxivity and indicates the effectiveness of the contrast agent in shortening the relaxation times of water protons. In the experiments presented here, we determined the relaxivity of the four iron(III) fumarate variants in a clinical MRI setting at $1.5 \mathrm{~T}$. These measurements were performed either in Xanthan gel (in case of the microparticle variants) or in water (in case of the spherical nanoparticles).

The mass-based relaxivities of the dipyramidal and needle-shaped iron(III) fumarate particles are inversely related to the particle size (Table 4). Surprisingly, the spherical nanoparticle sample do not follow this trend and have low $r_{2}$ values. In literature, other factors such as agglomeration, crystallinity and particle shape have been shown to influence the relaxivities of nanoparticles ${ }^{63-66}$. Experimentally determined mass-based relaxivities are additionally depicted as particle-based relaxivities
(Supporting Information, Figure S37). Here, both the $r_{1}$ and $r_{2}$ relaxivities of a single particle tend to increase with its size. This may be explained by the increasing number of paramagnetic iron centers in larger particles. To compare our results with commercially used contrast agents, the experimentally determined mass-based relaxivities were converted to molar relaxivities (Supporting Information, Figure S37). In this depiction the amount of iron(III) ions in the sample is considered. The iron(III) fumarate particles in this study achieve $3-8 \%$ of the molar relaxivities of iron-based $\mathrm{R}_{2}$ contrast agents such as Feridex (41 $\left.\mathrm{L} \mathrm{mmol}^{-1} \mathrm{~s}^{-1}\right)^{67}$. However, the dipyramidal nanoparticles have $\mathrm{R}_{1}$ relaxivities of the same magnitude as commercially available $\mathrm{R}_{1}$ contrast agents, with approximately $\sim 40 \%$ of the strength of gadoteric acid $\left(2.9 \mathrm{~L} \mathrm{mmol}^{-1} \mathrm{~s}^{-1}\right) .{ }^{67}$ These results confirm the overall potential of iron(III) fumarate as MRI contrast agent, especially since the particles can simultaneously be used in drug delivery.

Table 4. Mass-based relaxivities of iron(III) fumarate particles as determined in xanthan gel or in water (spherical nanoparticles).

\begin{tabular}{|c|c|c|}
\hline Morphology & $\begin{array}{c}\mathbf{r}_{\mathbf{1}} \\
{\left[\mathbf{s}^{-1}(\mathbf{m g} / \mathbf{m L})^{-1}\right]}\end{array}$ & $\begin{array}{c}\mathbf{r}_{2} \\
{\left[\mathbf{s}^{-1}(\mathbf{m g} / \mathbf{m L})^{-1}\right]}\end{array}$ \\
\hline \hline $\begin{array}{c}\text { Needle-shaped } \\
\text { Microparticles }\end{array}$ & $1.46 \pm 0.03$ & $8.6 \pm 0.5$ \\
\hline $\begin{array}{c}\text { Dipyramidal } \\
\text { Microparticles }\end{array}$ & $2.16 \pm 0.02$ & $15.7 \pm 0.2$ \\
\hline $\begin{array}{c}\text { Dipyramidal } \\
\text { Nanoparticles }\end{array}$ & $6.094 \pm 0.004$ & $18.8 \pm 0.4$ \\
\hline $\begin{array}{c}\text { Spherical Nano- } \\
\text { particles }\end{array}$ & $4.23 \pm 0.02$ & $5.93 \pm 0.03$ \\
\hline
\end{tabular}

\section{Biological characterization}

After establishing the synthesis of monodisperse iron(III) fumarate nano and microparticles and their physicial and functional characterization, we wanted to understand the impact of different morphologies on cellular interactions and biological criteria that are important for biomedical applications. To do this, we conducted toxicity and cell association experiments.

\section{Cellular interaction}

Fluorescence quenching effects make iron(III) fumarate particles hard to label and detect by fluorescence techniques, ${ }^{68}$ so instead cellular interaction and association were investigated by inductively coupled plasma optical emission spectroscopy (ICP-OES). In these experiments, the iron content in HeLa cells before and after incubation with the particles was compared. To do this, aqueous dispersions of the iron(III) fumarate variants were incubated with HeLa cells for $24 \mathrm{~h}$ at a concentration of $100 \mu \mathrm{g} / \mathrm{mL}$. Then the medium was separated from the cells, both fractions were dried and the iron-content of each fraction was determined via ICP-OES. This method allows us to compare the amount of iron associated with HeLa cells (membrane bound and internalized) and amount left in the supernatant. The relative amount of nanoparticles associated with the cells was then determined by relating the mass of iron(III) ions detected in the cell to the overall mass of iron(III) ions in the experiment (cells and supernatant). As a reference, nanoparticle-independent iron(III) uptake was tested using an iron(III) chloride-solution containing the same iron(III) amount as used in the particle uptake experiments. Additionally, the iron(III) content of the untreated cells was examined by the same method. The raw data from these experiments (see Table S8) suggests association of all four iron(III) fumarate variants with HeLa cells (15 to 66\%, 
Table 5). The untreated cells did not have any detectable levels of iron(III). Unspecific uptake of free $\mathrm{Fe}^{3+}$ caused by particle degradation is considered negligible because $\mathrm{Fe}^{3+}$ ion uptake in the control experiment was very low $(3 \%)$. In addition, stability measurements of the particles in cell culture medium showed that all particle types retained their morphology (so there was no reason to suspect any significant degradation). The micrometer sized particles produced the highest cellular iron increase; in general particle size could be correlated with cellular association. This observation may be explained by higher sedimentation and greater cellular uptake or external binding of larger particles in static cell culture conditions. Similar phenomena have also previously been described in context of other nanomaterials. ${ }^{69}$

Table 5. Fraction of iron(III) fumarate associated to HeLa cells after $24 \mathrm{~h}$ incubation as determined by ICP.

\begin{tabular}{|c|c|}
\hline Sample & Uptake \\
\hline \hline Spherical Nanoparticles & $(15.0 \pm 0.3) \%$ \\
\hline Dipyramidal Nanoparticles & $(29 \pm 1) \%$ \\
\hline Dipyramidal Microparticles & $(59 \pm 2) \%$ \\
\hline Needle-shaped Microparticles & $(66 \pm 3) \%$ \\
\hline Free Fe & $(3 \pm 0.5) \%$ \\
\hline
\end{tabular}

\section{Cytotoxicity}

Despite the identical chemical composition of all 4 iron(III) fumarate variants, their individual synthetic routes and unique morphologies could cause different effects on cellular metabolism and viability. To sasses the biological effects of each iron(III) fumarate type, human cervix carcinoma HeLa cells were incubated with aqueous dispersions of the individual particles at different concentrations. After $24 \mathrm{~h}, 48 \mathrm{~h}$ and $72 \mathrm{~h}$ the metabolic activity was determined in comparison to control cells without particle exposure by MTT (measuring cellular reduction potential) and CellTiter-Glo (measuring cellular ATP levels) assays. As shown in Figure 6 (MTT and CellTiterGlo), all iron(III) fumarate variants did not mediate distinct effects on cell viability within $24 \mathrm{~h}$ exposure at concentrations up to 200 $\mu \mathrm{g} / \mathrm{mL}$ (metabolic activity $>80 \%$ ). At high concentrations $(200 \mu \mathrm{g} / \mathrm{mL})$ and longer incubation times $(48 \mathrm{~h}$ and $72 \mathrm{~h})$ the cells showed reduced viability indicating beginning toxicity. This is especially prevalent for incubation with the spherical nanoparticles. A hypothetical explanation could be the induction of reactive oxygen species (ROS) generation by internalized iron(III). ROS generation was investigated with a ROSsensitive cell staining (2',7'-dichlorofluorescein diacetate, DCFDA) and flow cytometry (Figure S39). Here, slightly higher cellular fluorescence was detected after treatment with iron(III) fumarate particles, in particular with spherical morphology. Nevertheless, considering the high doses required for induction of effects on cell viability, all types of analyzed iron(III) fumarate particles are suggested to exhibit rather low cytotoxicity and adequate cellular tolerability. Notably, also the iron(III) fumarate variants synthesized in DMF did not exhibit an increased cytotoxicity compared to the variants synthesized in water.

\section{Conclusion}

At first glance, iron(III) fumarate seems to fulfill the strict requirements of nano- and microparticles to be used in biomedicine. However, the material possesses great morphological and structural variety (Table 1) and the impact on biomedical functionality and biocompatibility is insufficiently explored. In this work, the influence of different surfactant-free iron(III) fumarate synthesis methods have been explored and the result-
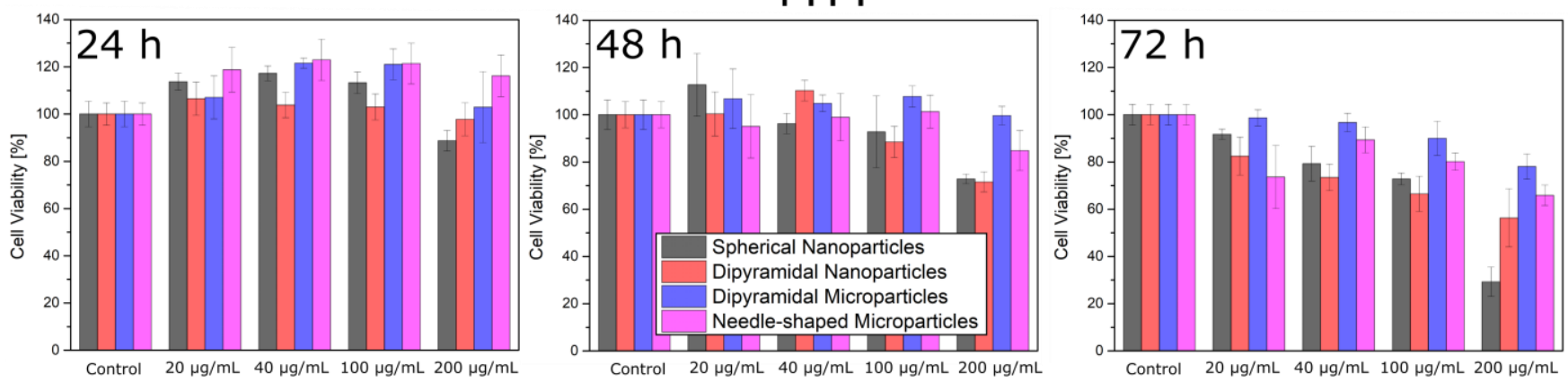

\section{CellTiterGlo}
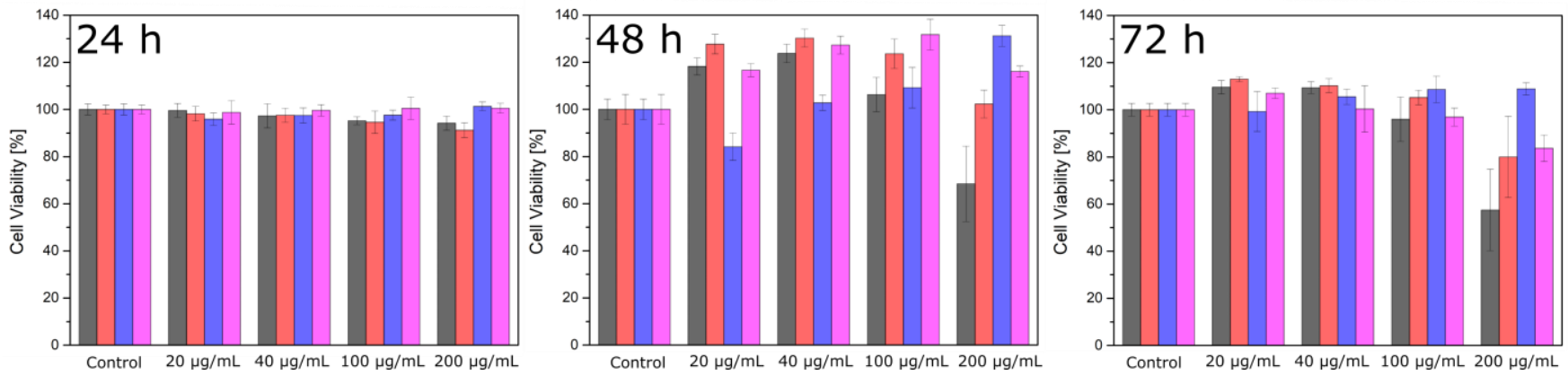

Figure 6. Cytotoxicity of iron(III) fumarate particles. Viability of HeLa cells after $24 \mathrm{~h}, 48 \mathrm{~h}$ and $72 \mathrm{~h}$ incubation with iron(III) fumarate particles as determined by MTT assay (top) and CellTiterGlo assay (bottom). 
ing particles characterized by X-ray diffraction, nitrogen sorption, thermogravimetry, spectroscopy, electron microscopy, MRI and biological assays.

Four different synthesis routes (RT precipitation, and solvothermal, microwave and microfluidic heating methods) were optimized in water and DMF. While the microfluidic approach addressed the fundamental challenges of controlled heat distribution and precise reaction time, solvothermal and microwave-based techniques were found to be better suited for scaling up production. In the water-based synthesis methods, iron(III) fumarate generation occurred in two-steps: first the formation of spherical iron(III) fumarate nanoparticles, then subsequent crystallization of needles. For iron(III) fumarate growth in DMF conventional heating in an oven and microfluidic reactor methods yielded micrometer sized particles. Microwave synthesis turned out to be the most efficient technique to generate dipyramidal nanoparticles. This technique enabled quick and facile production of homogeneous particles in large quantities. Overall this optimization resulted in 4 different homogenous varieties of iron(III) fumarate that spanned the nanoto microparticle scale and the individual synthesis procedures have potential for large scale production

Although all four materials are iron(III) fumarate by chemical composition, they differ in their porosity and functionality. All particle types crystallize in the MOF structure MIL-88, but the extent of crystallinity in the smallest nanoparticles is limited to a few nanometers. In-situ X-ray diffraction confirmed the typical breathing behavior of MIL-88A for all higher crystalline iron(III) fumarate variants. Lattice parameters and cell expanded up to $12 \%$ through solvent exchange, a desirable feature when designing materials for drug delivery since this expansion allows drug cargo to easily load. Regardless of the synthesis method, all iron(III) fumarate variants were shown to exhibit adequate cellular tolerability. Only at high concentrations $(200 \mu \mathrm{g} / \mathrm{mL})$ and long incubation times $(48 \mathrm{~h}$ and $72 \mathrm{~h})$ distinct effects on cell viability could be detected, especially in case of the spherical nanoparticles. Iron(III) fumarate also possesses interesting intrinsic functionality; its paramagnetic iron(III) centers render them suitable for MRI contrast agents. In MRI experiments the importance particle size optimization becomes apparent: by reducing the particle size of the higher crystalline iron(III) fumarate variants $r_{2}$ relaxivities can be doubled and $r_{1}$ relaxivities can be quadrupled.

We have studied the influence of morphological and structural optimization on nano and microparticles of iron(III) fumarate. Characterization of the resulting four particle variants was conducted to assess their applicability in biomedicine. Our study demonstrates the importance of precise synthesis control in improving the performance of such materials.

\section{Experimental Section}

Chemicals: Ethanol (VWR, 99.9\%), Iron(III) chloride hexahydrate (Grüssing, 99\%), Fumaric acid (Sigma, $\geq 99.0 \%$ ), N,N Dimethylformamide (DMF, VWR, 99.9\%), Xanthan gum from Xanthoma campestris (Sigma).

Synthesis of the $\mathbf{4}$ different Iron(III) fumarate Variants: In this short section, the synthesis protocols used to generate each of the four iron(III) fumarate variants that were later characterized for functionality and biocompatibility are shown.

Spherical Nanoparticles: A solution of $\mathrm{FeCl}_{3} \cdot 6 \mathrm{H}_{2} \mathrm{O}(2168 \mathrm{mg}, 8.02 \mathrm{mmol})$ in water $(40 \mathrm{~mL}$, Merck, Milli-Q) was prepared. Fumaric acid $(970 \mathrm{mg}, 8.36 \mathrm{mmol})$ was added under stirring. After incubation at room temperature ( $2 \mathrm{~min}$ ) the reaction was stopped and washed three times by centrifuging (7197 rcf, $20 \mathrm{~min}$ ) and redispersing in ethanol.

Needle-shaped Microparticles: A reaction mixture of fumaric acid (485 mg, $4.18 \mathrm{mmol})$ and $\mathrm{FeCl}_{3} \cdot 6 \mathrm{H}_{2} \mathrm{O}(1084 \mathrm{mg}$, $4.01 \mathrm{mmol})$ in water $(20 \mathrm{~mL}$, Merck, Milli-Q) was prepared. The reaction mixture was placed in a $50 \mathrm{~mL}$ Schott glass vial and put into an oven for $24 \mathrm{~h}$ at $80{ }^{\circ} \mathrm{C}$. The resulting particles were washed three times by centrifuging (7197 rcf, $20 \mathrm{~min}$ ) and redispersing in ethanol.

Dipyramidal Nanoparticles: Fumaric acid (485 mg, $4.18 \mathrm{mmol})$ and $\mathrm{FeCl}_{3} \cdot 6 \mathrm{H}_{2} \mathrm{O}(1084 \mathrm{mg}, 4.01 \mathrm{mmol})$ were dissolved in DMF $(20 \mathrm{~mL})$. This reaction mixture was placed in a $80 \mathrm{~mL}$ Teflon tubes and put in a microwave reactor (Synthos 3000 , Anton Paar) along with a reference solution containing $\mathrm{FeCl}_{3} \cdot 6 \mathrm{H}_{2} \mathrm{O}(1084 \mathrm{mg}, 4.01 \mathrm{mmol})$ in DMF $(20 \mathrm{~mL})$ and two additional vessels containing tap water $(20 \mathrm{~mL})$. A reaction program consisting of first heating the sample for $30 \mathrm{~s}$ up to $120^{\circ} \mathrm{C}$ and subsequent holding of this temperature for 5 min was used. At the end of this program the reaction was quenched by pouring the hot reaction mixture in DMF (room temperature, $50 \mathrm{~mL})$. The resulting product was washed with DMF $(40 \mathrm{~mL})$ washed three times by centrifuging (7197 rcf, $20 \mathrm{~min}$ ) and redispersing in DMF.

Dipyramidal Microparticles: A stock solution of fumaric acid (194 mg, $1.67 \mathrm{mmol})$ and $\mathrm{FeCl}_{3} \cdot 6 \mathrm{H}_{2} \mathrm{O}$ (433 mg, $\left.1.604 \mathrm{mmol}\right)$ in DMF $(8 \mathrm{~mL})$ was prepared and divided equally into eight $1.5 \mathrm{~mL}$ Eppendorf tubes. The reaction mixtures were placed in an oven for $30 \mathrm{~min}$ at $120^{\circ} \mathrm{C}$. The resulting particles were washed washed three times by centrifuging (16873 rcf, $10 \mathrm{~min}$ ) and redispersing in DMF.

\section{Additional Information}

Additional content for this publication is provided in the Supporting Information that can be accessed free of charge at http://pubs.acs.org. The following additional data is provided in the Supporting Information:

- Instrumental parameters and description of the setups

- Details on the screening of iron(III) fumarate particle growth (SEM micrographs, X-ray diffraction data)

- More detailed data and discussion for comparing the four iron(III) fumarate types: dynamic light scattering, Zeta-potential data, X-ray diffraction, in-situ X-ray diffraction, pair distribution function analysis, electron diffraction, nitrogen sorption,. thermogravimetry, particle size evaluation, MRI measurements

- Information on the biological assays: MTT, CellTiterGlo, reactive oxygen species, cellular association experiments

\section{$\bullet$}

\section{Acknowledgements:}

TDB wishes to thank the Royal Society for a University Research Fellowship (UF150021) and for their support. MT acknowledges funding from NanoDTC ESPSRC Grant EP/L015978/1, C.W.A. would like to thank the Royal Society for a PhD studentship (RG160498), and the Commonwealth Scientific and Industrial Research Organization (CSIRO) for additional support (C2017/3108). We acknowledge the provision of synchrotron access to Beamline I15-1 (EE 21260) at the Diamond Light 
Source, Rutherford Appleton Laboratory UK. We are grateful to Dr. Phil Chater and Dr. Dean Keeble for data collection during this rapid access time.

$\mathrm{PH}, \mathrm{KB}, \mathrm{MP}$, and SW are grateful for financial support from the Deutsche Forschungsgemeinschaft (DFG) through DFGproject WU 622/4-1 and PE 925/3-1, the Excellence Cluster Nanosystems Initiative Munich (NIM) and the Center for NanoScience Munich (CeNS).

PH wants to thank Steffen Schmidt and Tina Reuther and Jaraslova Obel for experimental support in Scanning Electron Microscopy, thermogravimetry and nitrogen sorption and ICP.

\section{REFERENCES}

1. Giner-Casares, J. J.; Henriksen-Lacey, M.; CoronadoPuchau, M.; Liz-Marzán, L. M., Inorganic nanoparticles for biomedicine: where materials scientists meet medical research. Mater. Today 2016, 19, (1), 19-28.

2. Mitragotri, S.; Burke, P. A.; Langer, R., Overcoming the challenges in administering biopharmaceuticals: formulation and delivery strategies. Nat Rev Drug Discov 2014, 13, (9), 655-72.

3. Dawidczyk, C. M.; Kim, C.; Park, J. H.; Russell, L. M.; Lee, K. H.; Pomper, M. G.; Searson, P. C., State-of-the-art in design rules for drug delivery platforms: lessons learned from FDA-approved nanomedicines. J Control Release 2014, 187, 133-44.

4. Yun, Y. H.; Lee, B. K.; Park, K., Controlled Drug Delivery: Historical perspective for the next generation. J Control Release 2015, 219, 2-7.

5. Lammers, T.; Kiessling, F.; Hennink, W. E.; Storm, G., Drug targeting to tumors: principles, pitfalls and (pre-) clinical progress. $J$ Control Release 2012, 161, (2), 175-87.

6. Faria, M.; Bjornmalm, M.; Thurecht, K. J.; Kent, S. J.; Parton, R. G.; Kavallaris, M.; Johnston, A. P. R.; Gooding, J. J.; Corrie, S. R.; Boyd, B. J.; Thordarson, P.; Whittaker, A. K.; Stevens, M. M.; Prestidge, C. A.; Porter, C. J. H.; Parak, W. J.; Davis, T. P.; Crampin, E. J.; Caruso, F., Minimum information reporting in bio-nano experimental literature. Nat Nanotechnol 2018, 13, (9), 777-785.

7. Hare, J. I.; Lammers, T.; Ashford, M. B.; Puri, S.; Storm, G.; Barry, S. T., Challenges and strategies in anti-cancer nanomedicine development: An industry perspective. Adv Drug Deliv Rev 2017, 108, 25-38.

8. Krug, H. F., Nanosafety research--are we on the right track? Angew. Chem. Int. Ed. Engl. 2014, 53, (46), 12304-19.

9. Freund, R.; Lachelt, U.; Gruber, T.; Ruhle, B.; Wuttke, S., Multifunctional Efficiency: Extending the Concept of Atom Economy to Functional Nanomaterials. ACS Nano 2018, 12, (3), 2094-2105.

10. Modena, M. M.; Ruhle, B.; Burg, T. P.; Wuttke, S., Nanoparticle Characterization: What to Measure? Adv. Mater. 2019 , e1901556.

11. Raliya, R.; Singh Chadha, T.; Haddad, K.; Biswas, P., Perspective on Nanoparticle Technology for Biomedical Use. Current Pharmaceutical Design 2016, 22, (17), 2481-2490.

12. Pelaz, B.; Alexiou, C.; Alvarez-Puebla, R. A.; Alves, F.; Andrews, A. M.; Ashraf, S.; Balogh, L. P.; Ballerini, L.; Bestetti, A.; Brendel, C.; Bosi, S.; Carril, M.; Chan, W. C.; Chen, C.; Chen, X.; Chen, X.; Cheng, Z.; Cui, D.; Du, J.; Dullin, C.; Escudero, A.; Feliu, N.; Gao, M.; George, M.; Gogotsi, Y.; Grunweller, A.; Gu, Z.; Halas, N. J.; Hampp, N.; Hartmann, R. K.; Hersam, M. C.; Hunziker, P.; Jian, J.; Jiang, X.; Jungebluth, P.; Kadhiresan, P.; Kataoka, K.; Khademhosseini, A.; Kopecek, J.; Kotov, N. A.; Krug, H. F.; Lee, D. S.; Lehr, C. M.; Leong, K. W.; Liang, X. J.; Ling Lim, M.; Liz-Marzan, L. M.; Ma, X.; Macchiarini, P.; Meng, H.; Mohwald, H.; Mulvaney, P.; Nel, A. E.; Nie, S.; Nordlander, P.; Okano, T.; Oliveira, J.; Park, T. H.; Penner, R. M.; Prato, M.; Puntes, V.; Rotello, V. M.; Samarakoon, A.; Schaak, R. E.; Shen, Y.; Sjoqvist, S.; Skirtach, A. G.; Soliman, M. G.; Stevens, M. M.; Sung, H. W.; Tang, B. Z.; Tietze, R.; Udugama, B. N.; VanEpps, J. S.; Weil, T.; Weiss, P. S.; Willner, I.; Wu, Y.; Yang, L.; Yue, Z.; Zhang, Q.; Zhang, Q.; Zhang, X. E.; Zhao, Y.; Zhou, X.; Parak, W. J.,
Diverse Applications of Nanomedicine. ACS Nano 2017, 11, (3), 23132381.

13. Tibbitt, M. W.; Dahlman, J. E.; Langer, R., Emerging Frontiers in Drug Delivery. J. Am. Chem. Soc. 2016, 138, (3), 704-17.

14. Surble, S.; Serre, C.; Mellot-Draznieks, C.; Millange, F.; Ferey, G., A new isoreticular class of metal-organic-frameworks with the MIL-88 topology. Chem Commun (Camb) 2006, (3), 284-6.

15. Mellot-Draznieks, C., Role of computer simulations in structure prediction and structure determination: from molecular compounds to hybrid frameworks. J. Mater. Chem. 2007, 17, (41), 4348.

16. Serre, C.; Mellot-Draznieks, C.; Surble, S.; Audebrand, N.; Filinchuk, Y.; Ferey, G., Role of solvent-host interactions that lead to very large swelling of hybrid frameworks. Science 2007, 315, (5820), 1828-31.

17. Mellot-Draznieks, C.; Serre, C.; Surble, S.; Audebrand, N.; Ferey, G., Very large swelling in hybrid frameworks: a combined computational and powder diffraction study. J. Am. Chem. Soc. 2005, 127, (46), 16273-8.

18. Serre, C.; Surble, S.; Mellot-Draznieks, C.; Filinchuk, Y.; Ferey, G., Evidence of flexibility in the nanoporous iron(iii) carboxylate MIL-89. Dalton Trans 2008, (40), 5462-4.

19. Illes, B.; Hirschle, P.; Barnert, S.; Cauda, V.; Wuttke, S.; Engelke, H., Exosome-Coated Metal-Organic Framework Nanoparticles: An Efficient Drug Delivery Platform. Chem. Mater. 2017, 29, (19), 8042-8046.

20. Illes, B.; Wuttke, S.; Engelke, H., Liposome-Coated Iron Fumarate Metal-Organic Framework Nanoparticles for Combination Therapy. Nanomaterials (Basel) 2017, 7, (11).

21. McKinlay, A. C.; Eubank, J. F.; Wuttke, S.; Xiao, B.; Wheatley, P. S.; Bazin, P.; Lavalley, J. C.; Daturi, M.; Vimont, A.; De Weireld, G.; Horcajada, P.; Serre, C.; Morris, R. E., Nitric Oxide Adsorption and Delivery in Flexible MIL-88(Fe) Metal-Organic Frameworks. Chem. Mater. 2013, 25, (9), 1592-1599.

22. Zhu, W.; Xiang, G.; Shang, J.; Guo, J.; Motevalli, B.; Durfee, P.; Agola, J. O.; Coker, E. N.; Brinker, C. J., Versatile Surface Functionalization of Metal-Organic Frameworks through Direct Metal Coordination with a Phenolic Lipid Enables Diverse Applications. Adv. Funct. Mater. 2018, 28, (16), 1705274.

23. Roder, R.; Preiss, T.; Hirschle, P.; Steinborn, B.; Zimpel, A.; Hohn, M.; Radler, J. O.; Bein, T.; Wagner, E.; Wuttke, S.; Lachelt, U., Multifunctional Nanoparticles by Coordinative Self-Assembly of HisTagged Units with Metal-Organic Frameworks. J. Am. Chem. Soc. 2017, 139, (6), 2359-2368.

24. Mejia-Ariza, R.; Rosselli, J.; Breukers, C.; Manicardi, A.; Terstappen, L. W.; Corradini, R.; Huskens, J., DNA Detection by Flow Cytometry using PNA-Modified Metal-Organic Framework Particles. Chemistry 2017, 23, (17), 4180-4186.

25. Horcajada, P.; Chalati, T.; Serre, C.; Gillet, B.; Sebrie, C.; Baati, T.; Eubank, J. F.; Heurtaux, D.; Clayette, P.; Kreuz, C.; Chang, J. S.; Hwang, Y. K.; Marsaud, V.; Bories, P. N.; Cynober, L.; Gil, S.; Ferey, G.; Couvreur, P.; Gref, R., Porous metal-organic-framework nanoscale carriers as a potential platform for drug delivery and imaging. Nat Mater 2010, 9, (2), 172-8.

26. Shang, W.; Zeng, C.; Du, Y.; Hui, H.; Liang, X.; Chi, C.; Wang, K.; Wang, Z.; Tian, J., Core-Shell Gold Nanorod@Metal-Organic Framework Nanoprobes for Multimodality Diagnosis of Glioma. Adv. Mater. 2017, 29, (3).

27. Mejia-Ariza, R.; Huskens, J., The effect of PEG length on the size and guest uptake of PEG-capped MIL-88A particles. Journal of Materials Chemistry B 2016, 4, (6), 1108-1115.

28. Jeong, G.-Y.; Ricco, R.; Liang, K.; Ludwig, J.; Kim, J.-O.; Falcaro, P.; Kim, D.-P., Bioactive MIL-88A Framework Hollow Spheres via Interfacial Reaction In-Droplet Microfluidics for Enzyme and Nanoparticle Encapsulation. Chem. Mater. 2015, 27, (23), 79037909 .

29. Gao, C.; Zhu, H.; Chen, J.; Qiu, H., Facile synthesis of enzyme functional metal-organic framework for colorimetric detecting $\mathrm{H}$ 2 O 2 and ascorbic acid. Chin. Chem. Lett. 2017, 28, (5), 1006-1012.

30. Wang, L.; Zhang, Y.; Li, X.; Xie, Y.; He, J.; Yu, J.; Song, Y., The MIL-88A-Derived Fe3O4-Carbon Hierarchical Nanocomposites for Electrochemical Sensing. Sci Rep 2015, 5, 14341. 
31. Dong, Z.; Le, X.; Liu, Y.; Dong, C.; Ma, J., Metal organic framework derived magnetic porous carbon composite supported gold and palladium nanoparticles as highly efficient and recyclable catalysts for reduction of 4-nitrophenol and hydrodechlorination of 4-chlorophenol. J. Mater. Chem. A 2014, 2, (44), 18775-18785.

32. Andrew Lin, K.-Y.; Hsu, F.-K., Magnetic iron/carbon nanorods derived from a metal organic framework as an efficient heterogeneous catalyst for the chemical oxidation process in water. RSC Advances 2015, 5, (63), 50790-50800.

33. Ke, F.; Luo, G.; Chen, P.; Jiang, J.; Yuan, Q.; Cai, H.; Peng, C.; Wan, X., Porous metal-organic frameworks adsorbents as a potential platform for defluoridation of water. J. Porous Mater. 2016, 23, (4), 1065-1073

34. Xu, W. T.; Ma, L.; Ke, F.; Peng, F. M.; Xu, G. S.; Shen, Y. H.; Zhu, J. F.; Qiu, L. G.; Yuan, Y. P., Metal-organic frameworks MIL88A hexagonal microrods as a new photocatalyst for efficient decolorization of methylene blue dye. Dalton Trans 2014, 43, (9), 3792-8.

35. Wang, J.; Wan, J.; Ma, Y.; Wang, Y.; Pu, M.; Guan, Z., Metal-organic frameworks MIL-88A with suitable synthesis conditions and optimal dosage for effective catalytic degradation of Orange $\mathrm{G}$ through persulfate activation. RSC Advances 2016, 6, (113), 112502112511.

36. Zhang, Y.; Zhou, J.; Chen, X.; Wang, L.; Cai, W., Coupling of heterogeneous advanced oxidation processes and photocatalysis in efficient degradation of tetracycline hydrochloride by Fe-based MOFs: Synergistic effect and degradation pathway. Chem. Eng. J. 2019, 369 , 745-757.

37. Liu, N.; Huang, W.; Zhang, X.; Tang, L.; Wang, L.; Wang, Y.; Wu, M., Ultrathin graphene oxide encapsulated in uniform MIL$88 \mathrm{~A}(\mathrm{Fe})$ for enhanced visible light-driven photodegradation of $\mathrm{RhB}$ Applied Catalysis B: Environmental 2018, 221, 119-128.

38. Shao, Z.; Zhang, D.; Li, H.; Su, C.; Pu, X.; Geng, Y., Fabrication of MIL-88A/g-C3N4 direct Z-scheme heterojunction with enhanced visible-light photocatalytic activity. Sep. Purif. Technol. 2019, 220, 16-24.

39. Park, S.-K.; Kim, J. K.; Kang, Y. C., Electrochemical properties of uniquely structured $\mathrm{Fe} 2 \mathrm{O} 3$ and $\mathrm{FeSe} 2$ /graphitic-carbon microrods synthesized by applying a metal-organic framework. Chem. Eng. J. 2018, 334, 2440-2449.

40. Li, Y.; Zhou, Y. X.; Ma, X.; Jiang, H. L., A metal-organic framework-templated synthesis of gamma- $\mathrm{Fe} 2 \mathrm{O} 3$ nanoparticles encapsulated in porous carbon for efficient and chemoselective hydrogenation of nitro compounds. Chem Commun (Camb) 2016, 52, (22), 4199202

41. Wang, Z.; Zhang, Z.; Xia, J.; Wang, W.; Sun, S.; Liu, L.; Yang, H., Fe2O3@C core@shell nanotubes: Porous Fe2O3 nanotubes derived from MIL-88A as cores and carbon as shells for high power lithium ion batteries. J. Alloys Compd. 2018, 769, 969-976.

42. Amaro-Gahete, J.; Klee, R.; Esquivel, D.; Ruiz, J. R.; Jimenez-Sanchidrian, C.; Romero-Salguero, F. J., Fast ultrasound-assisted synthesis of highly crystalline MIL-88A particles and their application as ethylene adsorbents. Ultrason. Sonochem. 2019, 50, 59-66.

43. Ramsahye, N. A.; Trung, T. K.; Scott, L.; Nouar, F.; Devic, T.; Horcajada, P.; Magnier, E.; David, O.; Serre, C.; Trens, P., Impact of the Flexible Character of MIL-88 Iron(III) Dicarboxylates on the Adsorption of n-Alkanes. Chem. Mater. 2013, 25, (3), 479-488.

44. Diego, A. G.; Sastre, G., From microscopic insights of H2 adsorption to uptake estimations in MOFs. Phys. Chem. Cheml. Phys. 2011, 13, 16558-16568.

45. Guan, Z.-Y.; Wang, Y.; Ma, Y.-W.; Wan, J.-Q.; Wang, J.M., Influence of Preparation Conditions of MIL-88A on Catalytic Degradation of Orange G and Dibutyl Phthalate. $3^{\text {rd }} 2017$ International Conference on Sustainable Development (SCSD 2017). 2017. DOI: 10.2991/icsd-17.2017.3

46. Chalati, T.; Horcajada, P.; Gref, R.; Couvreur, P.; Serre, C., Optimisation of the synthesis of MOF nanoparticles made of flexible porous iron fumarate MIL-88A. J. Mater. Chem. 2011, 21, (7), 22202227.

47. Bagherzadeh, E.; Zebarjad, S. M.; Madaah Hosseini, H. R.; Chagnon, P., Preparation, optimization and evolution of the kinetic mechanism of an Fe-MIL-88A metal-organic framework. CrystEngComm 2019, 21, (3), 544-553.

48. Bagherzadeh, E.; Zebarjad, S. M.; Hosseini, H. R. M., Morphology Modification of the Iron Fumarate MIL-88A Metal-Organic Framework Using Formic Acid and Acetic Acid as Modulators. Eur. J. Inorg. Chem. 2018, 2018, (18), 1909-1915.

49. Medvedev, P. V.; Soldatov, M. A.; Shapovalov, V. V.; Tereshchenko, A. A.; Gorban', I. E.; Fedorenko, A. G.; Soldatov, A. V., Analysis of the Local Atomic Structure of the MIL-88a Metal-Organic Framework by Computer Simulation Using XANES Data. JETP Letters 2018, 108, (5), 318-325.

50. Tsuruoka, T.; Furukawa, S.; Takashima, Y.; Yoshida, K.; Isoda, S.; Kitagawa, S., Nanoporous nanorods fabricated by coordination modulation and oriented attachment growth. Angew. Chem. Int. Ed. Engl. 2009, 48, (26), 4739-43.

51. McGuire, C. V.; Forgan, R. S., The surface chemistry of metal-organic frameworks. Chem Commun (Camb) 2015, 51, (25), 5199-217.

52. Paseta, L.; Seoane, B.; Julve, D.; Sebastian, V.; Tellez, C.; Coronas, J., Accelerating the controlled synthesis of metal-organic frameworks by a microfluidic approach: a nanoliter continuous reactor. ACS Appl Mater Interfaces 2013, 5, (19), 9405-10.

53. Jambovane, S. R.; Nune, S. K.; Kelly, R. T.; McGrail, B. P.; Wang, Z.; Nandasiri, M. I.; Katipamula, S.; Trader, C.; Schaef, H. T., Continuous, One-pot Synthesis and Post-Synthetic Modification of NanoMOFs Using Droplet Nanoreactors. Sci Rep 2016, 6, 36657.

54. Rubio-Martinez, M.; Batten, M. P.; Polyzos, A.; Carey, K. C.; Mardel, J. I.; Lim, K. S.; Hill, M. R., Versatile, high quality and scalable continuous flow production of metal-organic frameworks. Sci Rep 2014, 4, 5443.

55. Faustini, M.; Kim, J.; Jeong, G. Y.; Kim, J. Y.; Moon, H. R.; Ahn, W. S.; Kim, D. P., Microfluidic approach toward continuous and ultrafast synthesis of metal-organic framework crystals and hetero structures in confined microdroplets. J. Am. Chem. Soc. 2013, 135, (39), 14619-26

56. Pinna, A.; Ricco, R.; Migheli, R.; Rocchitta, G.; Serra, P. A.; Falcaro, P.; Malfatti, L.; Innocenzi, P., A MOF-based carrier for in situ dopamine delivery. RSC Advances 2018, 8, (45), 25664-25672.

57. Soper, A. K. GudrunN and GudrunX: Programs for Correcting Raw Neutron and X-ray Diffraction Data to Differential Scattering Cross Section; RAL-TR-2011-013; Rutherford Appleton Laboratory Technical Report: Oxfordshire, 2011.

58. Bennett, T. D.; Todorova, T. K.; Baxter, E. F.; Reid, D. G.; Gervais, C.; Bueken, B.; Van de Voorde, B.; De Vos, D.; Keen, D. A.; Mellot-Draznieks, C., Connecting defects and amorphization in UiO66 and MIL-140 metal-organic frameworks: a combined experimental and computational study. PCCP 2016, 18, (3), 2192-2201.

59. Zhou, C.; Longley, L.; Krajnc, A.; Smales, G. J.; Qiao, A.; Erucar, I.; Doherty, C. M.; Thornton, A. W.; Hill, A. J.; Ashling, C. W.; Qazvini, O. T.; Lee, S. J.; Chater, P. A.; Terrill, N. J.; Smith, A. J.; Yue, Y.; Mali, G.; Keen, D. A.; Telfer, S. G.; Bennett, T. D., Metal-organic framework glasses with permanent accessible porosity. Nat Commun 2018, 9, (1), 5042.

60. Farrow, C. L.; Juhas, P.; Liu, J. W.; Bryndin, D.; Bozin, E. S.; Bloch, J.; Proffen, T.; Billinge, S. J., PDFfit2 and PDFgui: computer programs for studying nanostructure in crystals. $J$ Phys Condens Matter 2007, 19, (33), 335219.

61. Horcajada, P.; Gref, R.; Baati, T.; Allan, P. K.; Maurin, G.; Couvreur, P.; Ferey, G.; Morris, R. E.; Serre, C., Metal-organic frameworks in biomedicine. Chem. Rev. 2012, 112, (2), 1232-68.

62. Peller, M.; Böll, K.; Zimpel, A.; Wuttke, S., Metal-organic framework nanoparticles for magnetic resonance imaging. Inorganic Chemistry Frontiers 2018, 5, (8), 1760-1779.

63. Vuong, Q. L.; Gillis, P.; Gossuin, Y., Monte Carlo simulation and theory of proton NMR transverse relaxation induced by aggregation of magnetic particles used as MRI contrast agents. J Magn Reson 2011, 212, (1), 139-48.

64. Vuong, Q. L.; Berret, J. F.; Fresnais, J.; Gossuin, Y.; Sandre, O., A universal scaling law to predict the efficiency of magnetic nanoparticles as MRI T(2)-contrast agents. Adv Healthc Mater 2012, 1, (4), $502-12$ 
65. Merbach, A.; Helm, L.; Tóth, É., The Chemistry of Contrast Agents in Medical Magnetic Resonance Imaging, $2^{\text {nd }}$ edition; John Wiley \& Sons, Ltd: Chichester, 2013.

66. Zhou, Z.; Yang, L.; Gao, J.; Chen, X., Structure-Relaxivity Relationships of Magnetic Nanoparticles for Magnetic Resonance Imaging. Adv. Mater. 2019, 31, (8), 1804567.

67. Rohrer, M.; Bauer, H.; Mintorovitch, J.; Requard, M.; Weinmann, H.-J., Comparison of magnetic properties of MRI contrast media solutions at different magnetic field strengths. Investigative Radiology 2005, 40, (11), 715-724.
68. Wuttke, S.; Braig, S.; Preiss, T.; Zimpel, A.; Sicklinger, J.; Bellomo, C.; Radler, J. O.; Vollmar, A. M.; Bein, T., MOF nanoparticles coated by lipid bilayers and their uptake by cancer cells. Chem Commun (Camb) 2015, 51, (87), 15752-5.

69. Cui, J.; Faria, M.; Bjornmalm, M.; Ju, Y.; Suma, T.; Gunawan, S. T.; Richardson, J. J.; Heidari, H.; Bals, S.; Crampin, E. J.; Caruso, F., A Framework to Account for Sedimentation and Diffusion in Particle-Cell Interactions. Langmuir 2016, 32, (47), 12394-12402.

\section{TOC:}

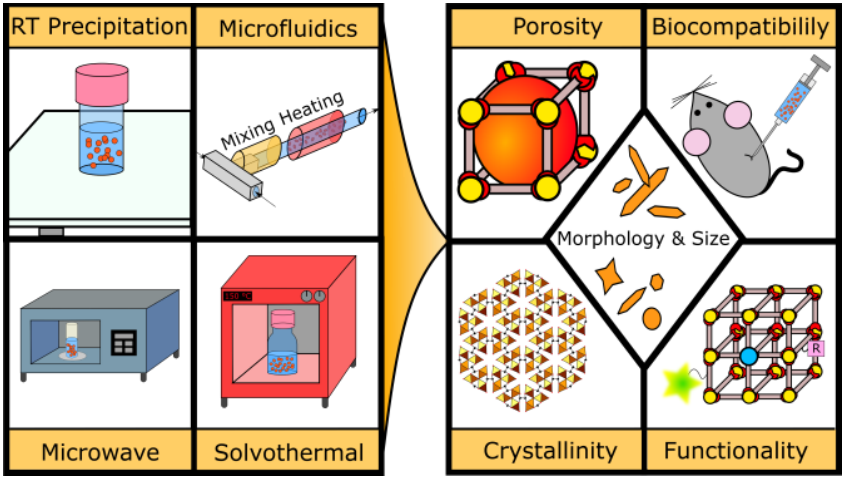

